\title{
Estabilización de fracturas conminutas no reducibles mediante fijadores híbridos en el tercio proximal de la tibia en caninos
}

\author{
Mauricio Jiménez Soto ${ }^{1} \bowtie$, Mauricio Pereira Mora ${ }^{2}$, Eddy Vega Acuña ${ }^{1}$ \\ 1 Hospital Especies Menores y Silvestres, Universidad Nacional, Costa Rica. Email: drjimenezsoto@hotmail.com, \\ Eddyva103@gmail.com \\ 2 Diagnóstico, control de enfermedades y manejo de animales silvestres. Email. matiscr@gmail.com
}

El objetivo de este trabajo fue la implementación de fijadores híbridos para la estabilización de fracturas conminutas no reducibles en el tercio proximal de la tibia. Como resultado de la utilización de fijadores híbridos se observó que el tiempo de cicatrización fue de ocho semanas, descargó peso en la extremidad a los tres días pos cirugía, el rango de movimiento de la articulación se conservó, no hubo reacción al material utilizado.

Se puede concluir que los fijadores híbridos son ideales para la reparación de fracturas conminutas no reducibles cerca de la articulación o transarticulares, el tiempo de cicatrización fue de ocho semanas, se conserva el rango de movimiento de la articulación, el paciente descarga peso en los primeros días pos cirugía, el material de los fijadores influye en la cicatrización y evolución del paciente.

凶 Autor para correspondencia Mauricio Jiménez Soto: drjimenezsoto@hotmail.com 